\title{
Women in nursing teams: organizational identification and experiences of pleasure and suffering ${ }^{1}$
}

\author{
Adriane Vieira ${ }^{2}$ \\ Marília Alves ${ }^{3}$ \\ Plínio Rafael Reis Monteiro ${ }^{4}$ \\ Fernando Coutinho Garcia ${ }^{5}$
}

\begin{abstract}
Objective: to analyze the degree of influence of the organizational identification on the experiences of pleasure and suffering of women who are members of the nursing staff of two general hospitals in Belo Horizonte. Method: a quantitative study was conducted with 97 nurses and 414 nursing technicians chosen by convenience in their workplaces. We used a self-administered questionnaire containing four Likert-type scales: self and hetero-perceptions; identification with the organization; and experiences of pleasure and pain at work. Results: the structural relations explained a small percentage of the variability of organizational identification, showing that the self and heteroperception are presented as relevant factors in professional identification with the organization. When considering how much the self and the hetero-perception and organizational identification all together impact in the experiences of pleasure and pain, a higher explanatory power is observed for: professional exhaustion, lack of recognition, freedom of expression and professional achievement. Descriptors: Gender Identity; Nursing; Self Concept; Women, Working.
\end{abstract}

\footnotetext{
${ }^{1}$ Supported by Conselho Nacional de Desenvolvimento Científico e Tecnológico (CNPq), process \# 402304/2010-1. ${ }^{2}$ PhD, Adjunct Profesor, Escola de Enfermagem, Universidade Federal de Minas Gerais, Belo Horizonte, MG, Brazil. ${ }^{3} \mathrm{PhD}$, Full Professor, Escola de Enfermagem, Universidade Federal de Minas Gerais, Belo Horizonte, MG, Brazil. ${ }^{4} \mathrm{PhD}$, Adjunct Professor, Universidade Fundação Mineira de Educação e Cultura, Belo Horizonte, MG, Brazil.

${ }^{5}$ PhD, Full Professor, Faculdade Novos Horizontes, Belo Horizonte, MG, Brasil.
} 


\section{Introduction}

Identity is built through the performance of roles, in a given social context, and mediated by the identification process, in which the 'other' plays a relevant role. Identity refers to the subject's self-perception in the interaction between the ' $\mathrm{I}$ ' and society and between the interior and the exterior. Identification, in turn, relates to the subject's achievement of the qualities of the 'other', with a view to raising his self-esteem. Through a set of identifications, the individual not only acknowledges 'who he is', but also gains the capacity to acknowledge himself as distinct, to perceive similarities and to understand collective life ${ }^{(1)}$. Identification takes place when the subjects' beliefs about the organization turn into a reference for his self-perception, generating a sense of belonging(2).

The subjective process of the individual's bonding with the organization and with work can result in experiences of pleasure and suffering. For work to be perceived mainly as a source of pleasure, the individual needs to receive proper recognition while accomplishing tasks ${ }^{(3)}$, deriving from two sources of judgment: utility and beauty. The first relates to the technical, social or economic relevance of the activity the worker performs, as judged by a hierarchical superior; the second refers to the singularity and specialty level of the work performed, aiming for recognition by evaluating colleagues. Identification with work and the organization will derive from the results of these judgments ${ }^{(4-5)}$.

In that context, the general aim in this paper is to analyze the extent to which self-perception and heteroperception influence organizational identification and the experiences of pleasure and suffering of female nursing team members at two general hospitals in Belo Horizonte/MG.

Historically, nursing has been characterized as a predominantly female and numerically representative profession in the hospital context ${ }^{(6)}$. Care actions focused on people in nursing teams' diagnostic and therapeutic processes mobilize a great emotional loading and can generate experiences of suffering at work. Hence, the relevance of this study relates to the analysis of whether the identification process with organizations and social recognition for one's work can minimize the suffering and project the pleasure.

A survey in health journals showed no publications that linked organizational identification with experiences of pleasure and suffering at work, nor scales to assess self- and hetero-perception. Also, most publications on identity and perception of professional image prioritize the use of qualitative methods. With a view to completing this knowledge gap, this paper proposes a quantitative model to analyze the behavior of the study variables.

\section{Method}

This descriptive, correlational and cross-sectional research with a quantitative approach involved 511 nursing team members at two general hospitals in Belo Horizonte/MG. Hospital "A" is affiliated with the municipal health network, exclusively functions within the Unified Health Network (SUS) and offers 409 beds, with a staff of 2,553 professionals. Hospital " $B$ " is nonprofit, delivers care to patients forwarded by health insurances and the SUS and offers 360 beds, with a 1,500-member staff.

Data were collected in November and December 2012. The participants' anonymity was guaranteed in compliance with the ethical principles of National Health Council Resolution 196/96. Approval for the research was obtained from the Research Ethics Committee at the hospitals: "A" (protocol 385866/2010 on 12/09/2012) and "B" (protocol 370/11 on 05/26/2011) and the study was conducted in compliance with ethical requirements. All participants signed the informed consent form and data confidentiality was guaranteed.

\section{Sample selection}

Based on the list of female nursing professionals at the two hospitals (" $A$ " and " $B$ "), the functional distribution of the employees was obtained, with 229 baccalaureate nurses and 1038 nursing technicians, as follows: 142 nurses and 614 nursing technicians at hospital " $\mathrm{A}$ "; and 87 nurses and 424 nursing technicians at hospital "B". With a $5 \%$ error margin and a $95 \%$ confidence level for finite population, the total sample was estimated at 511 subjects, including: 61 nurses and 224 nursing technicians at hospital " $\mathrm{A}$ " and 36 nurses and 190 nursing technicians at hospital "B".

The researcher's convenience, the availability of the women to participate in the research and at least six months on the job were used as inclusion criteria. Each nurse and nursing technician received a selfadministered questionnaire in their place of work, including instructions for completion. A deadline was set to return the completed questionnaire, with a maximum of three returns to collect all instruments. Data collection at each hospital was closed off after two weeks. 


\section{Study variables and data collection instrument}

The study variables and causal relations among them have been detailed in Figure 1.

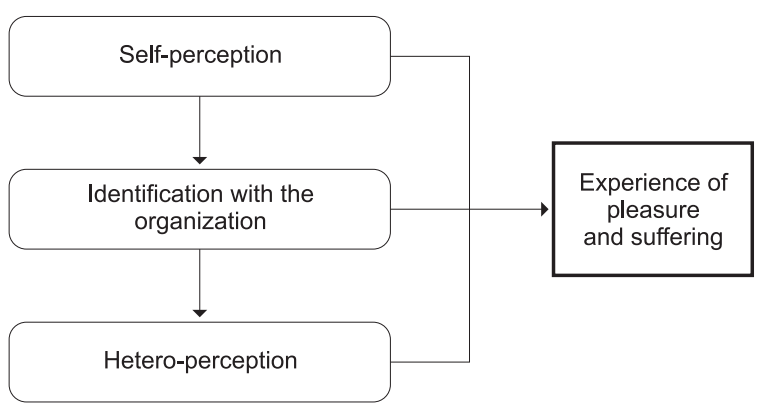

Figure 1 - Research Model

In the questionnaire, four model dimensions were considered:

- self-perception refers to the attributes the individual concedes to himself, related to personal and professional esteem;

- hetero-perception refers to what the individual considers the others attribute to him;

- organizational identification involves each individual's perceptions related to the sense of belonging to an organization, leading to a definition of himself with regard to the organization;

- experiences of pleasure and suffering at work refer to perceptions of pleasure and suffering related to work and the organization.

To assess how the individuals perceive their professional category, the Scale of Self-and Hetero-perception was applied, developed and validated for this study. To elaborate the scale, the lexical tradition was chosen, with adjectives characteristic of a certain professional category, linked with scores ranging from 1 (Describes very badly) to 5 (Describes very well), with the same number of positive and negative alternatives. The respondent scored each adjective twice: first considering the perception of the professional category (self-perception), followed by society's perception of that professional category (hetero-perception).

To validate the scale, a sample of 243 final-year nursing students was involved. The data were registered in the software Statistical Package for Social Sciences. After determining the baseline, dimensionality was assessed through exploratory factor analysis, for each dimension of the proposed scale, extracting the factors through main components analysis with the help of the scree plot analysis criterion. This resulted in a scale with 30 items, distributed in nine dimensions: dedication (friend, partner, dedicated, humane); effort (hard, exhausting, productive, hard-working); ethics (ethical, honest, honored, reliable); technicality (intelligent, wise, studious); innovation (creative, innovative); recognition (renowned, respected, admired, prestigious); accomplishment (optimistic, cheerful, happy); and subordination (obedient, submissive, dependent); dynamics (dynamic, stimulating, challenging).

To assess the questions about the organizational identification in the research model, the Organizational Identification Scale - OID was used, which consists of six previously validated factors: pride to work at the institution; happiness about being a member of the institution; strong sense of belonging to the institution; strong bonds with the institution; feeling of institutional support; sufficient knowledge about the institution ${ }^{(7)}$. To assess agreement with or disagreement from each of the situations, a five-point Likert scale was used.

To assess the questions about experiences of pleasure and suffering, the Scale of Indicators of Pleasure and Suffering at Work - EIPST was used. This scale is part of an inventory about work and risk of illness (ITRA), previously validated, built based on the theoretical framework of the psychodynamics of work and comprising four independent $\operatorname{scales}^{(8)}$. The EIPST consists of four dimensions, two for pleasure and two for suffering: the first indicates professional accomplishment and freedom of expression; the second emotional exhaustion and lack of recognition. The frequency of positive and negative experiences was assessed using a five-point Likert scale ( $1=$ never; $5=$ always). To maintain a valid and reliable instrument, the scale was reduced by applying Spearman-Brown's formula, maintaining a number of items in each of the four dimensions to permit a minimum reliability of 0.700 (Cronbach's alpha). This means that the employed instrument is a short version of the original(8).

The final block in the questionnaire contained sociodemographic information, including: age, education, number of children, time on the job at the hospital, work shift.

\section{Data recording and analysis}

The participants' answers were recorded in a database, using the software Statistical Package for Social Sciences, and analyzed with the help of Structura Equations Modeling and a multi-group approach. 
The analysis of the model variables shows that the largest number of missing data occurred in Q1.34, with $9.5 \%$ (53) of missing data, representing $3.8 \%$ of the base in hospital "A" (1068/[236*119]) and 3.66\% in hospital "B" $(1365 /[119 * 313])$, a relatively small percentage to indicate any threat against the integrity of the analyses ${ }^{(9)}$. Initially, cases with a loss of two standard deviations above the group average were excluded, and more than two standard deviations from the mean number of data missing from the base. Nine cases were excluded from each hospital database. These missing data were replaced through the so-called 'expectationmaximization' procedure, with a view to finding that maximum likelihood of parameters, resulting in 531 complete cases in the research sample.

The identification of extreme cases as those beyond the limits of \pm 2.58 from the mean revealed 609 extreme answers ( $0.96 \%$ of the base). These cases were replaced by less offensive values within the scale limits. The identification of multivariate extreme cases according to the Mahalanobis distance (measure of the standard distance of each point from the centroid in a multivariate correlated plan through which aberrant patterns can be identified and analyzed), in comparison with a chi-squared statistic with an $0.1 \%$ significance level and 119 degrees of freedom revealed four extreme cases for one hospital and 15 for the other. With a view to maintaining an appropriate sample size to test the model and assess the possible influence of the cases in the analysis, tests were accomplished with and without extreme cases in the research. The differences between the results were minimal and not perceptible, causing no changes in the study conclusions.

Next, compliance with the normality assumption was assessed through the $Z$ significance tests of kurtosis and skewness, as well as the Kolmogorov-Smirnov test. The skewness and kurtosis parameters in each group revealed significant ( $Z$ value beyond limits of \pm 1.96 ) and expressive (measures beyond the limits of \pm 1 ) discrepancies for practically all variables ${ }^{(10)}$. Similarly, the global significance tests demonstrated noticeable deviations from normality in the above mentioned groups, denoting a discrepancy that encourages the use of analytical methods more robust against the violation of the normality assumption, in this case the Partial Least Squares (PLS) method. In addition, the linearity and multicollinearity assumptions were assessed through the Variance Inflation Factor (VIF), the scatterplots (for 100 pairs of variables) and the sample correlation matrix. Evidences demonstrated that the redundancy level (VIF below 10 and correlations between \pm 0.9 ) and the previous mentioned assumptions were achieved.

Next, the quality of the scales was assessed through the Exploratory Factor Analysis (extraction through principal axis analysis and direct oblimin rotation). Initially, the self-perception responses were used for the test, followed by the hetero-perception responses. The results of this assessment showed that some indicators did not fall into their respective factors, although the hetero-perception scale revealed good conceptual coherence. Given the goal of using the difference between the perceptions and their influence on the identification and on experiences of pleasure and suffering, in the analysis, the difference between these indicators was applied to identify the underlying factors.

\section{Results}

In the total sample at the two hospitals, $48.2 \%$ of the women had no children and $44,2 \%$ had one or two children; $44.2 \%$ were single and $42.9 \%$ married. As regards education, $68.5 \%$ held a secondary/technical degree, $15.7 \%$ undergraduate and $13.7 \%$ specialization. Concerning their time on the job at the hospital, $26.4 \%$ had worked there less than one year, $49.9 \%$ between one and five years and $18.9 \%$ more than ten years; $19 \%$ were baccalaureate nurses and $81 \%$ nursing technicians; $73.3 \%$ worked day shifts. The mean age was 36.77 years (standard deviation $=9.97$ ).

Table 1 indicates the results of the exploratory factor analysis:

Table 1 - Exploratory Factor Analysis: scale of self- and hetero-perception

\begin{tabular}{|c|c|c|c|c|c|c|c|c|}
\hline \multirow{2}{*}{ Indicators } & \multicolumn{8}{|c|}{ Number of factors } \\
\hline & 1 & 2 & 3 & 4 & 5 & 6 & 7 & 8 \\
\hline \multicolumn{9}{|l|}{ Dedication } \\
\hline Friend & 0.06 & -0.05 & 0.86 & -0.03 & 0.05 & 0.02 & 0.06 & 0.01 \\
\hline Partner & -0.01 & -0.06 & 0.77 & 0.10 & 0.00 & 0.01 & 0.00 & 0.01 \\
\hline Humane & 0.17 & 0.21 & 0.41 & -0.06 & -0.15 & 0.00 & -0.01 & 0.09 \\
\hline Dedicated & 0.06 & 0.22 & 0.33 & -0.03 & -0.24 & 0.03 & 0.08 & $\begin{array}{r}0.16 \\
\text { ntinu }\end{array}$ \\
\hline
\end{tabular}


Table 1 - (continuation)

\begin{tabular}{|c|c|c|c|c|c|c|c|c|}
\hline \multirow{2}{*}{ Indicators } & \multicolumn{8}{|c|}{ Number of factors } \\
\hline & 1 & 2 & 3 & 4 & 5 & 6 & 7 & 8 \\
\hline \multicolumn{9}{|l|}{ Technicality } \\
\hline Wise & 0.78 & -0.02 & 0.06 & 0.03 & 0.00 & 0.04 & 0.00 & 0.10 \\
\hline Intelligent & 0.71 & 0.03 & 0.06 & 0.08 & -0.09 & 0.00 & 0.01 & 0.06 \\
\hline Studious & 0.45 & 0.12 & 0.10 & 0.04 & -0.01 & 0.23 & 0.00 & 0.02 \\
\hline Challenging & 0.45 & 0.10 & -0.06 & 0.06 & -0.29 & 0.06 & 0.03 & 0.02 \\
\hline \multicolumn{9}{|l|}{ Effort } \\
\hline Hard-working & 0.05 & 0.72 & 0.02 & 0.04 & 0.02 & 0.00 & -0.04 & 0.05 \\
\hline Hard & 0.04 & 0.69 & 0.00 & 0.00 & 0.10 & -0.07 & 0.08 & 0.05 \\
\hline Exhausting & 0.01 & 0.65 & -0.01 & -0.08 & 0.00 & 0.07 & 0.00 & -0.04 \\
\hline Productive & 0.00 & 0.47 & -0.05 & 0.08 & -0.22 & -0.03 & 0.05 & 0.02 \\
\hline \multicolumn{9}{|l|}{ Recognition } \\
\hline Prestigious & 0.04 & -0.06 & -0.02 & 0.94 & 0.08 & 0.01 & 0.00 & 0.01 \\
\hline Renowned & -0.01 & -0.09 & 0.05 & 0.66 & -0.04 & 0.05 & 0.05 & -0.02 \\
\hline Admired & 0.07 & 0.13 & 0.01 & 0.55 & -0.03 & -0.05 & -0.02 & 0.04 \\
\hline Respected & -0.06 & 0.09 & 0.11 & 0.15 & -0.06 & 0.08 & -0.29 & 0.03 \\
\hline \multicolumn{9}{|l|}{ Dynamics } \\
\hline Dynamic & 0.08 & -0.04 & 0.01 & 0.02 & -0.68 & -0.01 & 0.05 & 0.14 \\
\hline Stimulating & 0.10 & -0.04 & 0.02 & 0.08 & -0.33 & 0.37 & 0.04 & -0.04 \\
\hline \multicolumn{9}{|l|}{ Innovation } \\
\hline Creative & 0.08 & 0.00 & 0.05 & -0.04 & -0.78 & 0.00 & -0.09 & 0.06 \\
\hline Innovative & 0.05 & 0.02 & 0.00 & 0.03 & -0.60 & 0.04 & 0.08 & 0.00 \\
\hline \multicolumn{9}{|l|}{ Accomplishment } \\
\hline Cheerful & 0.14 & -0.03 & 0.05 & 0.01 & 0.00 & 0.69 & 0.02 & 0.02 \\
\hline Happy & 0.02 & -0.04 & -0.02 & 0.00 & -0.01 & 0.86 & 0.00 & 0.05 \\
\hline Optimistic & -0.02 & 0.06 & 0.05 & 0.02 & 0.04 & 0.70 & 0.07 & 0.07 \\
\hline \multicolumn{9}{|l|}{ Subordination } \\
\hline Dependent & -0.04 & 0.06 & 0.14 & 0.04 & -0.12 & 0.06 & 0.52 & 0.03 \\
\hline Submissive & 0.04 & 0.08 & 0.03 & 0.05 & 0.02 & 0.06 & 0.52 & 0.04 \\
\hline Obedient & -0.08 & 0.10 & 0.15 & 0.10 & -0.07 & 0.13 & 0.43 & 0.13 \\
\hline \multicolumn{9}{|l|}{ Ethics } \\
\hline Ethical & -0.02 & -0.05 & 0.00 & 0.00 & -0.05 & -0.01 & -0.02 & 0.90 \\
\hline Honest & 0.04 & 0.01 & 0.00 & 0.04 & 0.02 & -0.04 & 0.06 & 0.86 \\
\hline Reliable & 0.09 & 0.03 & 0.04 & -0.07 & 0.02 & 0.09 & 0.01 & 0.70 \\
\hline Honored & 0.03 & 0.07 & -0.07 & 0.08 & -0.08 & 0.30 & -0.06 & 0.35 \\
\hline Cronbach's Alpha & 0,86 & 0.76 & 0.81 & 0.76 & 0.82 & 0.86 & 0.66 & 0.87 \\
\hline
\end{tabular}

Kaiser Meyer Olkin $(\mathrm{KMO})$ Measure of sampling adequacy $=0.918$. Extracted variance $=67.9$. Favorable measures for the application of EFA ${ }^{(10)}$

The dimensions found are compatible with what is expected by the scales and demonstrates that the items are in line with the scales included in the study, except for the indicators 'stimulating' and 'dynamic' in the 'dynamics' dimension, which were transferred to the dimensions 'innovation' and 'accomplishment', respectively.

For the scale of experiences of pleasure and suffering at work ${ }^{(8)}$, after the exclusion of four items (freedom to use my creativity, insecurity, fear and uselessness) from those initially selected for the instrument ${ }^{(8)}$, due to low communality and/or crossed loadings, a satisfactory factorial solution was reached, as demonstrated in Table 2.

The results for the analysis of organizational identification resulted in a single factor, as expected(7) (Table 3). 
Table 2 - Exploratory Factor Analysis: scale of experiences of pleasure and suffering at work

\begin{tabular}{|c|c|c|c|c|}
\hline \multirow{2}{*}{ Indicators } & \multicolumn{4}{|c|}{ Number of factors } \\
\hline & 1 & 2 & 3 & 4 \\
\hline \multicolumn{5}{|l|}{ Lack of recognition } \\
\hline Injustice & 0.83 & 0.07 & -0.01 & 0.03 \\
\hline Devaluation & 0.80 & -0.02 & 0.04 & 0.05 \\
\hline Indignation & 0.75 & -0.03 & 0.09 & 0.10 \\
\hline Discrimination & 0.68 & 0.02 & -0.11 & -0.07 \\
\hline Lack of recognition of my effort & 0.67 & -0.05 & 0.06 & 0.14 \\
\hline Disqualification & 0.57 & -0.06 & -0.08 & -0.05 \\
\hline \multicolumn{5}{|l|}{ Professional accomplishment } \\
\hline Professional accomplishment & -0.03 & 0.76 & 0.03 & -0.10 \\
\hline Identification with my tasks & 0.01 & 0.74 & -0.04 & 0.12 \\
\hline Wellbeing & -0.01 & 0.72 & 0.03 & -0.16 \\
\hline Pride about what I do & 0.02 & 0.68 & 0.00 & 0.02 \\
\hline Personal gratification as a result of my activities & -0.03 & 0.52 & 0.10 & -0.08 \\
\hline \multicolumn{5}{|l|}{ Freedom of speech } \\
\hline Cooperation among colleagues & 0.05 & -0.04 & 0.86 & 0.00 \\
\hline Trust among colleagues & 0.01 & 0.01 & 0.77 & -0.02 \\
\hline Solidarity among colleagues & -0.02 & 0.06 & 0.65 & -0.01 \\
\hline Freedom to express my opinions at the workplace & -0.22 & 0.05 & 0.44 & -0.05 \\
\hline \multicolumn{5}{|l|}{ Professional exhaustion } \\
\hline Stress & -0.09 & -0.03 & -0.04 & 0.96 \\
\hline Emotional exhaustion & 0.02 & 0.01 & -0.05 & 0.80 \\
\hline Overload & 0.20 & -0.01 & 0.01 & 0.59 \\
\hline Frustration & 0.25 & -0.13 & 0.01 & 0.47 \\
\hline Cronbach's Alpha & 0,84 & 0.84 & 0.80 & 0.87 \\
\hline
\end{tabular}

$\mathrm{KMO}=0.900$. Variance $=65.2 \%$, considering total data variability. Favorable measures for the application of $\mathrm{EFA}^{(10)}$

Table 3 - Exploratory Factor Analysis: organizational identification

\begin{tabular}{lc}
\hline \multicolumn{1}{c}{ Indicators } & Factor \\
\cline { 2 - 2 } & 1 \\
\hline I feel proud to work for this hospital & 0.86 \\
I am happy to be a member of this hospital & 0.85 \\
I experience a strong feeling of belonging to this hospital & 0.81 \\
I feel strong bonds with this hospital & 0.79 \\
I feel that people support me at this hospital & 0.71 \\
I am sufficiently knowledgeable about this hospital & 0.45 \\
\hline
\end{tabular}

$\mathrm{KMO}=0.871$. Variance $=63.62 \%$, considering total data variability. Favorable measures for the application of EFA(10)

Next, the general quality of the measures was assessed, using Cronbach's Alpha, Compound Reliability (CR) and Average Variance Extracted (AVE). These measures represent the general reliability of scales/ factors and indicators. Cronbach's Alpha and Compound Reliability indicated the percentage of variance attributed to the actual score of the latent variable, that is, the variance percentage free from random measurement errors. Values typically higher than 0.700 are accepted but, for scales under construction, values up to 0.600 can be included(9). These measures show that the scales possess acceptable properties, as most values are superior to 0.800 . The AVErepresents the mean reliability of the indicators and should be higher than 0.400 , which was the case for all of the scales.

Then, the validity of the measures was assessed through the construct validity procedure ${ }^{(9)}$ and the structural equations modeling approach was applied for this purpose(11), using the partial least squares estimation method, which is the most appropriate given the relation between sample and model size and the presence of deviations from normality ${ }^{(12)}$.

Construct validity consists of three components: convergent validity; discriminant validity and nomological validity. In convergent validity, the intent is to identify whether all indicators originate in the same factor, which means the evaluation of whether the factor loadings of the indicators are significant at $5 \%$ or $1 \%$ one-tailed ${ }^{(12)}$. This criterion revealed that practically all indicators complied with the proposed requisite with good reliability, given that the squared coefficient of the standardized factor loadings was higher than 0.4 in most cases. To measure discriminant validity ${ }^{(12)}$, the Average 
Variance Extracted of the indicators was compared with the squared coefficient of the correlations between the pairs of constructs. All scales demonstrated discriminant validity according to these criteria. The results of the preceding analysis demonstrated that the constructs possess discriminant validity. Finally, the general research model was applied to the presented data. Using the bootstrap method, it was verified which relations between self- and hetero-perception were statistically significant at $5 \%$ of one-tailed significance (Table 4 ).

Table 4 - Structural relations tested in complete sample

\begin{tabular}{|c|c|c|c|}
\hline Structural relations & Weight* & Error ${ }^{\dagger}$ & T Value F $^{\prime}$ \\
\hline \multicolumn{4}{|l|}{ Scales: self-hetero-perception/pleasure-suffering } \\
\hline Dedication/Professional exhaustion & -0.11 & 0.05 & 1.97 \\
\hline Dedication/Lack of recognition & 0.03 & 0.04 & 0.68 \\
\hline Dedication/Freedom of speech & 0.18 & 0.07 & 2.53 \\
\hline Dedication/Professional accomplishment & 0.05 & 0.04 & 1.08 \\
\hline Effort/Professional exhaustion & 0.18 & 0.05 & 3.91 \\
\hline Effort/Lack of recognition & 0.11 & 0.05 & 2.34 \\
\hline Effort/Freedom of speech & -0.11 & 0.05 & 2.30 \\
\hline Effort/Professional accomplishment & -0.08 & 0.04 & 1.82 \\
\hline Innovation/Professional exhaustion & -0.02 & 0.04 & 0.70 \\
\hline Innovation/Lack of recognition & -0.02 & 0.03 & 0.70 \\
\hline Innovation/Freedom of speech & 0.01 & 0.04 & 0.27 \\
\hline Innovation/Professional accomplishment & 0.04 & 0.04 & 1.03 \\
\hline Accomplishment/Professional exhaustion & -0.18 & 0.05 & 3.57 \\
\hline Accomplishment/Lack of recognition & -0.19 & 0.05 & 3.73 \\
\hline Accomplishment/Freedom of speech & 0.15 & 0.06 & 2.72 \\
\hline Accomplishment/Professional accomplishment & 0.20 & 0.05 & 4.41 \\
\hline Recognition/Professional exhaustion & -0.08 & 0.04 & 1.98 \\
\hline Recognition/Lack of recognition & -0.11 & 0.05 & 2.12 \\
\hline Recognition/Freedom of speech & -0.03 & 0.03 & 1.09 \\
\hline Recognition/Professional accomplishment & 0.14 & 0.04 & 3.27 \\
\hline Subordination/Professional exhaustion & 0.06 & 0.04 & 1.36 \\
\hline Subordination/Lack of recognition & 0.06 & 0.04 & 1.45 \\
\hline Subordination/Freedom of speech & 0.01 & 0.04 & 0.26 \\
\hline Subordination/Professional accomplishment & -0.01 & 0.03 & 0.35 \\
\hline Technicality/Professional exhaustion & 0.16 & 0.06 & 2.70 \\
\hline Technicality/Lack of recognition & 0.15 & 0.06 & 2.60 \\
\hline Technicality/Freedom of speech & -0.09 & 0.06 & 1.48 \\
\hline Technicality/Professional accomplishment & -0.12 & 0.06 & 2.01 \\
\hline Ethics/Professional exhaustion & 0.16 & 0.05 & 2.86 \\
\hline Ethics/Lack of recognition & 0.15 & 0.05 & 2.80 \\
\hline Ethics/Freedom of speech & -0.05 & 0.05 & 0.98 \\
\hline Ethics/Professional accomplishment & -0.08 & 0.05 & 1.52 \\
\hline \multicolumn{4}{|l|}{ Scales: self-hetero-perception/identification } \\
\hline Dedication/Organizational identification & -0.09 & 0.06 & 1.40 \\
\hline Effort/Organizational identification & -0.12 & 0.05 & 2.32 \\
\hline Innovation/Organizational identification & 0.14 & 0.07 & 2.06 \\
\hline Accomplishment/Organizational identification & 0.19 & 0.06 & 3.02 \\
\hline Recognition/Organizational identification & 0.11 & 0.05 & 2.13 \\
\hline Subordination/Organizational identification & -0.03 & 0.04 & 0.71 \\
\hline Technicality/Organizational identification & -0.18 & 0.07 & 2.67 \\
\hline Ethics/Organizational identification & -0.09 & 0.06 & 1.40 \\
\hline \multicolumn{4}{|l|}{ Scales: identification/pleasure-suffering } \\
\hline Organizational identification/Professional exhaustion & -0.31 & 0.04 & 7.19 \\
\hline Organizational identification/Lack of recognition & -0.35 & 0.04 & 8.10 \\
\hline Organizational identification/Freedom of speech & 0.32 & 0.05 & 6.91 \\
\hline Organizational identification/Professional accomplishment & 0.41 & 0.04 & 9.31 \\
\hline
\end{tabular}

*Weight: weight of structural relation assessed in the model

tError: standard error of weight

¥T-value: statistics of significance test of structural relation (if higher than $1.96 p<0.05$ two-tailed, if higher than $1.645 p<0.05$ one-tailed) 
In general, the structural relations explained a small percentage of the variance in organizational identification $\left(R^{2}=8.5 \%\right)$, demonstrating that the difference between self- and hetero-perception is a hardly relevant factor in the professional's identification with his organization. When considering the extent to which self- and heteroperception and organizational identification influence the experiences of pleasure and suffering, greater explanatory power is observed for: 1) professional exhaustion $\left.\left(R^{2}=25.06 \%\right) ; 2\right)$ lack of recognition $\left.\left(R^{2}=27.47 \%\right) ; 3\right)$ freedom of speech $\left(R^{2}=16.67 \%\right)$ and; 4) professional accomplishment $\left(R^{2}=28.38 \%\right)$. This analysis complies with the central research objective, which was to establish the correlation between self/ hetero-perception, organizational identification and experiences of pleasure and suffering at work.

\section{Discussion}

For the dimension 'dedication' in the scale of selfand hetero-perception of the professional category, a negative relation was observed with 'professional exhaustion' and a positive relation with 'freedom of speech' (in the scale of experiences of pleasure and suffering at work). This finding reveals that the nurses who assess their profession as 'humane', 'partner', 'friend' and 'dedicated' and get recognition from society for these attributes tend to feel less frustrated and overburdened and more gratified, and also perceive cooperation and trust among colleagues.

The dimension 'effort' in the scale of self- and heteroperception exerted a significant and negative influence on all dimensions of pleasure, and a significant positive influence on all dimensions of suffering. In addition, a strong negative relation existed with organizational identification. This result reveals that the perception of a profession that requires great effort in daily work causes considerable displeasure and suffering, and also mitigates the professional's identification with his organization. This feeling gains even greater prominence when society does not recognize the self-assessed effort. These results are a source of concern, as it is indicated in other studies that weak professional identification can negatively affect workers' physical and mental health(13) and good professional performance(14). It should be highlighted that, historically, women's vocational ideology in nursing is based on caregiving, unselfish, dedicated, delicate and gentle qualities, that is, typically female qualities, besides its performance under medical authority, whose professional category is mainly male(15-16).
The dimension 'innovation' in the scale of selfand hetero-perception exerted a significant positive impact on organizational identification only, revealing that individuals who assess their profession as creative and innovative develop greater affinity with their organization. As observed, innovation is strongly related with the challenges the leaderships confront their teams with. This, in turn, can enhance the group's identification and further the collective belief in the ability to execute different tasks in complex environments(17). Hence, the group's identification with the leadership, which at bottom represents the organization, is core to the development of the group's self-confidence.

Professionals who perceive their profession as happy and optimistic, items in the dimension 'accomplishment' of the scale of self- and hetero-perception, tend to experience less suffering and greater pleasure in their work, as well as further identification with the organization. These relations were significant at $5 \%$ onetailed, revealing this dimension's great predictive power in the construction of the professional self-image and of positive attitudes and postures towards organizations. This result confirms that individuals' identification with the organization is strongly affected by the perception that the organization is procedurally fair and treats the team members with respect ${ }^{(18)}$.

A professional image of 'prestige' and 'reputation' in the dimension 'recognition' on the scale of self- and hetero-perception culminates in less suffering and greater professional accomplishment. This dimension was also important to determine the organizational identification, indicating that professional recognition significantly affects the identification with the organization ( $p<0.05$ ).

In this study, the dimension 'subordination' on the scale of self- and hetero-perception was not important in the experiences of pleasure and suffering, nor in organizational identification, given that none of these relations was statistically significant. In that sense, the data support the understanding that the nursing teams deny the discourse of subordination and inferiorization of nurses when compared to physicians; that situation is characterized as this professional category's main imaginary confrontation ${ }^{(19)}$.

The dimension 'technicality', which refers to the profession's intellectual challenges, showed to be a factor that strengthens suffering and reduces pleasure, except for 'freedom of speech'. Therefore, it is inferred that professionals who believe that their profession is highly technical and assess that society perceives it 
possesses low intellectual complexity tend to experience greater suffering and less pleasure.

The dimension 'ethics' only affected the experience of suffering at work, with positive relations. This demonstrates that, as the self-perception of high ethical standards inherent in the profession increases, while society does not recognize these standards, professional suffering increases.

The variable organizational identification, in turn, exerted a strong positive influence on experiences of pleasure and a negative influence on experiences of suffering.

\section{Conclusion}

The general aim in this paper was to analyze the influence of self-perception and hetero-perception on the organizational identification and experiences of pleasure and suffering of female nursing team members at two general hospitals in Belo Horizonte/MG. In conclusion, the organizational identification variable exerts a considerable positive impact on the experiences of pleasure and a negative impact on the experiences of suffering. On the other hand, no causal relation could be established between self- and hetero-perception and organizational identification. In other words, it cannot be affirmed that, the more positive the self- and heteroperception and the greater the agreement between both, the higher the individuals' degree of identification with the organization will be. The present results cannot be compared either with others, as no similar studies have been found in the scientific literature.

The methodological limitation of this research is related to the sample size, which could be expanded to permit conceptually more robust statistical analyses like structural equations modeling, using the analysis of covariance structures. For future research, qualitative analyses are also suggested, with a view enhancing the interpretation of the study variables' behavior.

The explanatory percentages found reveal fertile ground to assess the influence of other individual (personality, values, life experience) and contextual factors (quality of life at work, infrastructure, remuneration) on organizational identification as well as on experiences of pleasure and suffering at work in future studies.

\section{References}

1. Fernandes MER, Marques AL, Carrieri AP. Identidade organizacional e os componentes do processo identificatório: uma proposta de integração. Cad Ebape. $2009 ; 7(4): 688-703$.
2. Bizumic B, Reynolds KJ, Turner JC, Bromhead D, Subasic, E. The role of the group in individual functioning: school identification and the psychological well-being of staff and students. Appl Psychol. 2009; 58(1):171-92.

3. Gernet I, Dejours C. Évaluation du travail et reconnaissance. Nouvell Reve Psychosociol. 2009;8(2):27-36.

4. Dejours C. Addendum da psicopatologia à psicodinâmica do trabalho. In: Lancman S, Sznelwar LI. Christophe Dejours: da psicopatologia à psicodinâmica do trabalho. Rio de Janeiro: Fiocruz, Brasília: Paralelo 15; 1993/2008. p. 163-78.

5. Brant LC, Minayo-Gomez C. Manifestação do sofrimento e resistência ao adoecimento na gestão do trabalho. Saúde Soc. 2009;18(2):237-47.

6. Rossetti AC, Gaidzinski RR. Estimating the nursing staff required in a new hospital. Rev. Latino-Am. Enfermagem. 2011;19(4):1011-7.

7. Almeida ALC A Influência da identidade projetada sobre a reputação organizacional [tese de doutorado]. Belo Horizonte (MG): Programa de Pós-graduação em Administração da Universidade Federal de Minas Gerais; 2005. 361 p.

8. Mendes AM. Psicodinâmica do trabalho: teoria, método e pesquisas. São Paulo (SP): Casa Psi; 2007. p. 29-48.

9. Cooper DR, Pamela SS. Marketing research. New York: McGraw-Hill; 2006. 412p.

10. Hair JF, Black WC, Babin BJ, Anderson RE. Multivariate data analysis. 7th. New Jersey: Prentice Hall, Upper Saddle River; 2010. 960 p.

11. Bagozzi RP, Yi Y. Multitrait-multimethod matrices in consumer research. J Consumer Res. 1991; 17(4):426-39.

12. Fornell C, Bookstein F. Two structural equation models: LISREL and PLS applied to consumer exit-voice theory. J Marketing Res. 1982;19(4):440-52.

13. Haslam SA, Jetten J, Postmes T, Haslam C. Social identity, health and well-being: An emerging agenda for applied psychology. Appl Psychol. 2009;58(1):1-23. 14. Bizumic B, Reynolds K J, Meyers B. Predicting social identification over time: the role of group and personality factors. Pers Individ Dif. 2012;53(4):453-8.

15. Santo TBE, Oguisso T, Fonseca RMGS. The professionalization of Brazilian nursing in the written media of the end of the nineteenth century: a gender analysis. Rev. Latino-Am. Enfermagem. 2011;19(5):1265-71. 
16. Brito MJM, Montenegro LC, Alves M. Relational experiences of power and gender for nurse-managers of private hospitals. Rev. Latino-Am. Enfermagem. 2010;18(5):952-9.

17. Lee C, Farh JL, Chen ZJ. Promoting group potency in project teams: The importance of group identification. J Organiz Behav. 2011;32:1147-62.

18. Blader SL, Tyler TR. Testing and extending the group engagement model: Linkages between social identity, procedural justice, economic outcomes, and extra role behavior. J Appl Psychol. 2009;94:445-64.

19. Moreira MCN. Images in the venus' mirror: woman, nursing and modernity. Rev. Latino-Am. Enfermagem. 1999;7(1):55-65. 